\title{
Giant Ovarian Cyst Presenting With Colon Cancer
}

\author{
Evan Robinson ${ }^{\mathrm{a}, \mathrm{c}}$, Cesar Aguiluz ${ }^{\mathrm{b}}$, Andrew McCague ${ }^{\mathrm{b}}$, Vivian Joseph Davis ${ }^{\mathrm{b}}$
}

\begin{abstract}
Giant ovarian cysts have become rare, likely due to improved and more frequent imaging techniques, especially in the United States. We present the case of a 71-year-old female that presented with one of the largest documented post-menopausal ovarian cysts in the United States, measuring $26 \mathrm{~cm}$ and weighing $9.2 \mathrm{~kg}$ (20.28 lbs), with a concomitant colon adenocarcinoma. A total abdominal hysterectomy, right salpingo-oophorectomy, and right hemicolectomy were performed.
\end{abstract}

Keywords: Giant ovarian cysts; Colon adenocarcinoma; Adnexal mass

\section{Introduction}

Ovarian cancer is the second most common gynecological cancer and the fifth leading cause of cancer death in women in the United States [1]. The surface epithelial-stromal tumors are the most common type and serous are the most common subtype [2]. Approximately 14-18\% of women over 50 have unilocular cystic ovarian tumors, but the prevalence of cysts over $6-10 \mathrm{~cm}$ is only 2 in 1,000 in this age group $[3,4]$. Less than five cases of a unilocular ovarian cyst larger than $26 \mathrm{~cm}$ have been documented, all of which were reported outside of the United States [5-8].

Ovarian cysts are typically asymptomatic and often discovered incidentally, but may present with pelvic pain and/ or menstrual changes. Most can be treated symptomatically with pain control and monitored for progression. However, if large enough, they may cause obstructive symptoms such as nausea, vomiting, abdominal pain, distention and early satiety. Due to the rare incidence of giant ovarian cysts, the clinician may be unlikely to consider them as a diagnosis when evaluating a patient with these symptoms.

We present the removal of a giant ovarian cyst and concomitant colon adenocarcinoma in an elderly female.

\section{Case Report}

A 71-year-old African American G2P1 female presented to the Women's Health Clinic for abdominal pain and distention progressing over the past year. Her past medical history included hypertension and type II diabetes. A large pelvic mass was discovered on ultrasound at this time, confirmed by CT to be an approximately $20 \mathrm{~cm}$ cystic mass of the ovary. She was admitted to OB/GYN, but her hospital stay was complicated by the discovery of a saddle pulmonary embolus that required intubation and ICU care. The patient was deemed unstable for surgery and was asked to follow-up with the clinic after her medical problems had been stabilized.

Six months later, the patient presented to the same clinic complaining of abdominal pain and shortness of breath, $\mathrm{SpO}_{2}$ was $85 \%$. She was transferred to the emergency department to rule out pulmonary embolism.

In the emergency department, the patient was in acute

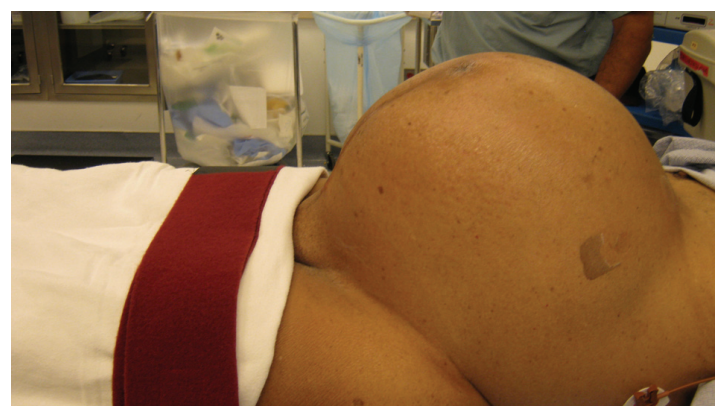

Figure 1. Patient in theater with hugely distended abdomen.

\footnotetext{
Manuscript accepted for publication September 26, 2013
${ }^{\mathrm{a}}$ Western University of Health Sciences, 309 E Second Street, Pomona, CA 911711, USA
${ }^{\mathrm{b}}$ Arrowhead Regional Medical Center, 400 N Pepper Drive, Colton, CA 92324, USA
${ }^{\mathrm{c}}$ Corresponding author: Evan Robinson, Western University of Health Sciences, 309 E Second Street, Pomona, CA 911711, USA.

Email: evankrobinson@gmail.com
}

doi: http://dx.doi.org/10.4021/jcs196w 


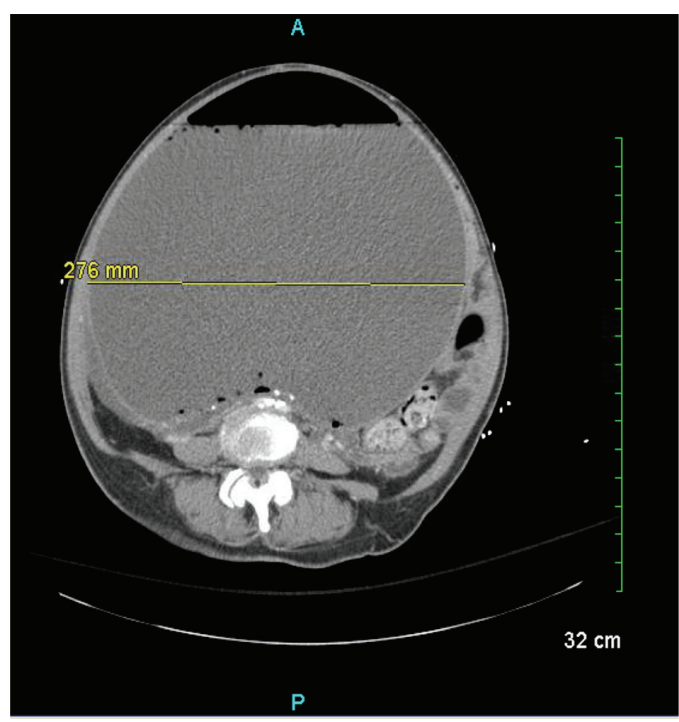

Figure 2. Computed tomography scan of patient's abdomen at ED presentation demonstrating $28 \mathrm{~cm}$ fluid filled mass.

distress, reporting 10/10 left-lower-quadrant pain, nausea, vomiting, and early satiety. Her blood pressure was 148/81 $\mathrm{mmHg}$, pulse rate $110 \mathrm{bpm}$, respiratory rate $20 \mathrm{bpm}$, temperature $97.6^{\circ} \mathrm{F}$. Her abdomen was severely distended (Fig. 1), firm and non-tender. Upon CT of the abdomen and pelvis, it was found that the mass had enlarged to at least $28 \mathrm{~cm}$ (Fig. 2 ), occupying most of the abdomen and was likely causing the patient's current symptoms.

Laboratory results showed hemoglobin of $9.9 \mathrm{~g} / \mathrm{dL}$, white blood cell count $15.6 \times 10^{3}$, and INR 4.4. Tumor markers were obtained due to obstructive symptoms and anemia, revealing CEA $32.4 \mathrm{ng} / \mathrm{mL}$, and CA-125 $192.9 \mathrm{U} / \mathrm{mL}$, and GI was consulted. Colonoscopy discovered a right-sided colonic mass without evidence of metastasis.

The patient was stabilized and taken to surgery for a right hemicolectomy and resection of a large pelvic tumor (Fig. 3). A right difficult oophorectomy was performed. This was followed by a total abdominal hysterectomy with left salpingo-oophorectomy, right retroperitoneal periaortic lymphadenectomy, right hemicolectomy with terminal ileum and ileocolonic anastomosis. Pathology weighed the specimen and found it to be $9.2 \mathrm{~kg}(20.28 \mathrm{lbs})$. The mass was found to be a benign unilocular cyst without an inner lining, of unknown origin. Biopsy of the colon was found to be moderately well differentiated stage II T3N0M0 adenocarcinoma. It was concluded that resection was adequate and adjuvant therapy was not necessary.

The patient was found to have a left common femoral vein DVT on post-op day three and was treated with anticoagulants and coumadin. She remained stable with good respiratory effort throughout the remainder of her stay and was discharged home. At follow-up, abdominal and early satiety

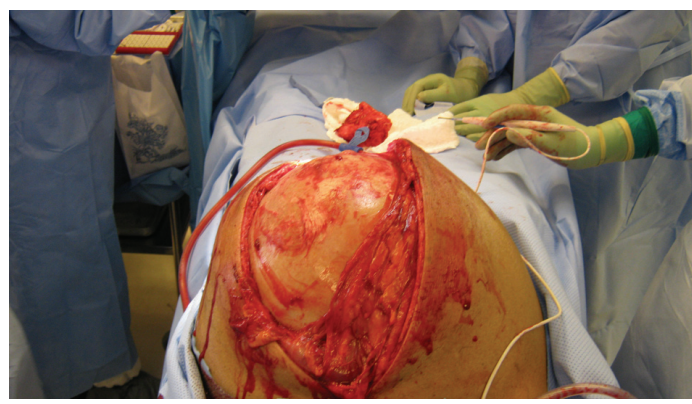

Figure 3. Initial exposure of giant ovarian cyst.

symptoms resolved.

\section{Discussion}

Due to the widespread use of modern imaging techniques such as ultrasound and CT, the incidence of giant ovarian tumors is exceedingly rare in industrialized nations [5, 9]. Documented giant ovarian cysts also tend to be reported from developing countries rather than industrialized nations. This likely reflects the decreased access to modern healthcare found in these countries.

About $0.2 \%$ of women over 50 that undergo transvaginal ultrasound screening will have a cyst above $6-10 \mathrm{~cm} \mathrm{[3].}$ To our knowledge, our patient had the largest ovarian cyst in a postmenopausal woman in the United States. Ovarian tumors may be symptomatic or incidentally discovered. If symptomatic they may present with lower abdominal pain and enlargement with associated mass-effect symptoms (urinary frequency, GI complaints, and so on). If the adnexal mass has been deemed low-risk in a postmenopausal patient, it may be monitored or followed depending on size and symptoms. A mass greater than $10 \mathrm{~cm}$ or that has abdominal, constitutional, urinary, or pelvic symptoms indicates surgical exploration

If discovered incidentally on $\mathrm{CT}$, labs should be drawn for a CA-125 level. A mass under $5 \mathrm{~cm}$ and a normal CA- 125 $(<35 \mathrm{U}$ per $\mathrm{mL})$ in a postmenopausal woman is virtually always benign. If an adnexal mass is discovered clinically, the patient should first undergo transvaginal ultrasound (TVS) along with a CA-125 level. If the TVS demonstrate a cyst $<$ $5 \mathrm{~cm}$ and a normal CA-125, the patient may undergo observation.

Due to the rarity of giant ovarian cysts, their surgical management has not been well studied with randomized trials. However, giant symptomatic cysts, or complex ovarian tumors over five centimeters or patient with a rising CA-125 should have surgery $[10,11]$. Traditionally, all giant cysts were treated with laparotomy, but laparoscopy has become popular and may be appropriate in certain cases, especially uncomplicated smaller cysts. Laparoscopy may be appropri- 
ate for patients with a very low risk of malignancy, and has been well documented in premenopausal patients $[12,13]$. Accurate staging of ovarian tumors is also similar between laparotomy and laparoscopy; however laparoscopy is associated with higher rates of tumor rupture [14]. Laporoscopy was deemed inappropriate for our patient due to the extreme size of the cyst as well as the concomitant colon adenocarcinoma, therefore an open approach was selected.

It is important to recognize ovarian cysts as a potential cause for abdominal distention and their ability to exert a significant mass effect that can lead to cardiopulmonary compromise.

\section{References}

1. Siegel R, Naishadham D, Jemal A. Cancer statistics, 2013. CA Cancer J Clin. 2013;63(1):11-30.

2. Lacey JS, M. Ovarian Neoplasm. In: Robboy MG, editor. Robboy's Pathology of the Female Reproductive Tract: Churchill Livingstone Elsevier. 2009; p. 601.

3. Modesitt SC, Pavlik EJ, Ueland FR, DePriest PD, Kryscio RJ, van Nagell JR, Jr. Risk of malignancy in unilocular ovarian cystic tumors less than 10 centimeters in diameter. Obstet Gynecol. 2003;102(3):594-599.

4. Greenlee RT, Kessel B, Williams CR, Riley TL, Ragard LR, Hartge P, Buys SS, et al. Prevalence, incidence, and natural history of simple ovarian cysts among women $>55$ years old in a large cancer screening trial. Am J Obstet Gynecol. 2010;202(4):373 e371-379.

5. Suntharasaj T, Sriwongpanich S, Sorapipat C. The larg- est ovarian cyst in Songklanagarind Hospital: a case report. J Med Assoc Thai. 1994;77(8):445-448.

6. Agarwal V, Sachdev A, Singh R, Lehl S, Basu S. Autoimmune hemolytic anemia associated with benign ovarian cyst: a case report and review of literature. Indian J Med Sci. 2003;57(11):504-506.

7. Menahem S, Shvartzman P. Giant ovarian cyst mimicking ascites. J Fam Pract. 1994;39(5):479-481.

8. Peng YY, Chen CP, Chien SC, Chen JR. Torsion of a huge ovarian cyst in a 90-year-old woman. Taiwan J Obstet Gynecol. 2008;47(2):224-225.

9. Symmonds RE, Spraitz AF, Jr., Koelsche GA. Large Ovarian Tumor. Report of a Case. Obstet Gynecol. 1963;22:473-477.

10. van Nagell JR, DePriest PD. Management of adnexal masses in postmenopausal women. Am J Obstet Gynecol. 2005;193(1):30-35.

11. Spencer JA, Gore RM. The adnexal incidentaloma: a practical approach to management. Cancer Imaging. 2011;11:48-51.

12. Alobaid A, Memon A, Alobaid S, Aldakhil L. Laparoscopic management of huge ovarian cysts. Obstet Gynecol Int. 2013;2013:380854.

13. Murawski M, Golebiewski A, Sroka M, Czauderna P. Laparoscopic management of giant ovarian cysts in adolescents. Wideochir Inne Tech Malo Inwazyjne. 2012;7(2):111-113.

14. Covens AL, Dodge JE, Lacchetti C, Elit LM, Le T, Devries-Aboud M, Fung-Kee-Fung M. Surgical management of a suspicious adnexal mass: a systematic review. Gynecol Oncol. 2012;126(1):149-156. 